\title{
Antibiotic Resistance of Diverse Bacteria from Aquaculture in Borneo
}

\author{
M. M. Kathleen, L. Samuel, C. Felecia, E. L. Reagan, A. Kasing, M. Lesley, and S. C. Toh \\ Department of Molecular Biology, Faculty of Resource Science and Technology, Universiti Malaysia Sarawak, \\ 94300 Kota Samarahan, Sarawak, Malaysia \\ Correspondence should be addressed to L. Samuel; lsamuel@frst.unimas.my
}

Received 2 May 2016; Revised 28 July 2016; Accepted 29 August 2016

Academic Editor: Marcel H. Zwietering

Copyright (C) 2016 M. M. Kathleen et al. This is an open access article distributed under the Creative Commons Attribution License, which permits unrestricted use, distribution, and reproduction in any medium, provided the original work is properly cited.

The administration of antimicrobials in aquaculture provides a selective pressure creating a reservoir of multiple resistant bacteria in the cultured fish and shrimps as well as the aquaculture environment. The objective of this study was to determine the extent of antibiotic resistance in aquaculture products and aquaculture's surrounding environment in Sarawak, Malaysian Borneo. Ninetyfour identified bacterial isolates constituted of 17 genera were isolated from sediment, water, and cultured organisms (fish and shrimp) in selected aquaculture farms. These isolates were tested for their antibiotic resistance against 22 antibiotics from several groups using the disk diffusion method. The results show that the highest resistance was observed towards streptomycin (85\%, $n=20)$, while the lowest resistance was towards gentamicin $(1.1 \%, n=90)$. The multiple antibiotic resistant (MAR) index of the isolates tested ranged between 0 and 0.63 . It was suggested that isolates with MAR index $>0.2$ were recovered from sources with high risk of antibiotic resistant contamination. This study revealed low level of antibiotic resistance in the aquaculture bacterial isolates except for streptomycin and ampicillin $(>50 \%$ resistance, $n=94)$ which have been used in the aquaculture industry for several decades. Antibiotic resistant patterns should be continuously monitored to predict the emergence and widespread of MAR. Effective action is needed to keep the new resistance from further developing and spreading.

\section{Introduction}

Since the discovery of penicillin in 1928 by a Scottish scientist Alexander Fleming followed by the release of many other earlier drugs onto the market to treat infection, the development of drug resistance in various sectors including aquaculture has been reported [1-3]. The misuse and abuse of the antimicrobial drugs are among the important factors that have contributed to the rise of resistant microbes around the world. Antibiotics, which have saved millions of lives and were also known as miracle drug in the past, are no longer the ultimate way for the treatment of infections because bacteria have continued to develop multiple resistance towards many different types or classes of the drugs [4].

Antimicrobial agents have been widely used in fish farming for either therapeutic, prophylactic, or other purposes [5]. The antibiotics are normally used to increase growth as well as feed efficiency in the animals [6]. However, some of the antibiotics have been frequently used in both veterinary and human medicine such as sulfonamides, chloramphenicol, tetracycline, nitrofurans [5], oxytetracycline [7], neomycin, erythromycin, streptomycin, prefuran, and enrofloxacin [8]. The evolution of bacteria towards antibiotic resistance has been accelerated distinctly by selective pressure due to inappropriate and overuse of the antibiotics $[3,9]$. In the efforts to cope with this problem, scientists have accelerated the search for alternative antimicrobial agents by screening many potential sources including medicinal plants $[10,11]$ and microbes $[12,13]$.

Aquaculture is an important sector in the agriculture industry and is rapidly growing to meet the world's demands for protein source. This sector is challenged with the diverse type of diseases and bacterial infections; and antibiotics are an excellent tool to circumvent the problem $[14,15]$. The presence of bacteria with multiple antibiotic resistance found in food products has become a threat to public health as 
there is potential that the carried or acquired genes are transferred to other bacteria of clinical significance [16-18]. Some antibiotics which are commonly used in food-producing animals are also used in human medicine, reducing the antibiotic's efficiency when treating infections and increasing the morbidity and mortality associated with diseases. The resistance limits the choice of antibiotics for the disease treatment $[4,16,19,20]$.

The use of antibiotics needs to be monitored from time to time to evaluate the emergence and spread of bacterial resistance towards antimicrobial agents [5, 21]. There is limited data on the antibiotic resistance of bacteria in fish and other cultured organisms sampled directly from fish farms as well as the aquaculture environment. Therefore, this study aims to determine this.

\section{Materials and Methods}

2.1. Bacterial Strains. Sampling was carried out at aquaculture farms located at selected districts in Sarawak, Malaysian Borneo, including Kuching, Bintulu, Limbang, Miri, and Sampadi (Lundu). Three types of samples were collected which were the sediment, water, and cultured species. Cultured species refers to fish or shrimp. In Kuching, Bintulu, and Miri, the cultured organisms collected were the fish while in Limbang and Sampadi (Lundu), the cultured organisms collected were shrimps. Sampling and sample processing were performed according to standard operating protocol by [22]. The isolation, designation, and identification of the isolates were carried out as reported by Kathleen and coworkers earlier [23]. The list of bacteria and their source of origin are listed in Table 1.

2.2. Antibiotic Susceptibility Tests. Ninety-four bacterial isolates from 17 different genera [23] were assessed for their susceptibility to different antibiotics utilizing the disk diffusion method according to method described by Clinical and Laboratory Standards Institutes (CLSI) [24] on MuellerHinton agar (MHA). The bacterial groups and the antibiotics tested are listed in Table 1. Briefly, fresh bacterial culture with $0.5 \mathrm{McF}$ arland turbidity was swabbed onto the MHA surface using sterile cotton buds. Commercial antimicrobial discs (Oxoid, UK) were evenly embedded onto the inoculated agar incubated at $37^{\circ} \mathrm{C}$ for 18 to 24 hours. Escherichia coli strain from American Type Culture Collection (ATCC) 25922 was used as control.

2.3. Data Collection and Analysis. The diameter of complete inhibition zone formed around the antibiotic discs was measured to the nearest whole millimeter using standardized ruler. The results obtained were analyzed as resistant or susceptible according to standard interpretative table by CLSI [25] and Bonnet [26]. Multiple antibiotic resistance (MAR) index was then determined for each isolate by dividing the number of antibiotics to which an isolate is resistant with the total number of antibiotics tested [2]. The MAR index is an indicator to identify the risk contamination that is potentially hazardous to human. Calculated value of more than 0.2 indicates that the isolates were isolated from high risk sources [27].

\section{Results}

In this study, commonly used antibiotics in both veterinary and human medicine were selected for the antibiotic susceptibility testing. The antibiotic selection also depends on the bacterial genera because different bacterial genera require different classes of antibiotics for optimal antibacterial activity. Some of the antibiotics were not tested in this study because some bacterial genera are naturally resistant to certain classes of antibiotics; hence the antibiotics were excluded from the analysis. The antibiotic profile of the bacterial isolates from the aquaculture fish and shrimps and their environment is shown in Table 1.

The bacterial isolates showing the top five highest percentages of resistant were towards streptomycin $(85 \%, n=$ $20)$, followed by ampicillin $(56.8 \%, n=74)$, penicillin $(47.1 \%$, $n=51)$, erythromycin $(43.1 \%, n=51)$, and cephalotin $(42.3 \%, n=71)$. The bacterial isolates showing the top five highest percentages of susceptible were towards gentamicin $(1.1 \%, n=90)$, followed by tobramycin $(2.2 \%, n=90)$, chloramphenicol $(4.0 \%, n=75)$, norfloxacin $(5 \%, n=80)$, and amikacin $(5.6 \%, n=90)$. The other bacterial isolates and their percentage of resistant are shown in Table 1.

In this study, the antibiotic resistant patterns for all isolates were also determined to monitor the spread of antibiotic resistance. Sixty-one different antibiotic resistance patterns were observed among the isolates through this study (data not shown). The resistance patterns were highly variable; 20.2\% ( $n=94)$ isolates have no resistance towards any antibiotics tested, $16 \%(n=94)$ isolates were resistant to only one antibiotic, and 63.8\% $(n=94)$ isolates were resistant to multiple antibiotics. Chryseobacterium spp. isolated from water in Limbang aquaculture farm was resistant towards 12 out of 19 antibiotics tested, which was the highest amount of antibiotic resistance observed in this study.

Most isolates $(53.2 \%, n=94)$ possess distinctive pattern. However, there are also patterns (11 patterns) shared by 2 or more bacteria isolates. The pattern shared by most isolates (19 isolates, $n=94$ ) is $0 \%$ resistance (MAR index equal to 0 ). There is at least an isolate with $0 \%$ resistance towards all antibiotics tested in all sampling locations except for Bintulu. There is difference in the resistance pattern for bacteria isolated from water, sediment, and the cultured organisms. Bacteria that were isolated from the same pond and same source of origin (sediment, water, or cultured organisms) possess different antibiotic patterns. This may be due to the genus and species difference of the bacteria isolates. The antibiotic resistant patterns of the bacterial genera are more influenced by the location from where the isolates were isolated rather than their genus.

Multiple antibiotic resistant (MAR) index analysis was introduced by Krumperman in 1983 [27]. This analysis has been used to group the different sources from where the bacteria were recovered using the frequency of antibiotics resistance [28]. Isolates with MAR $<0.2$ were determined 


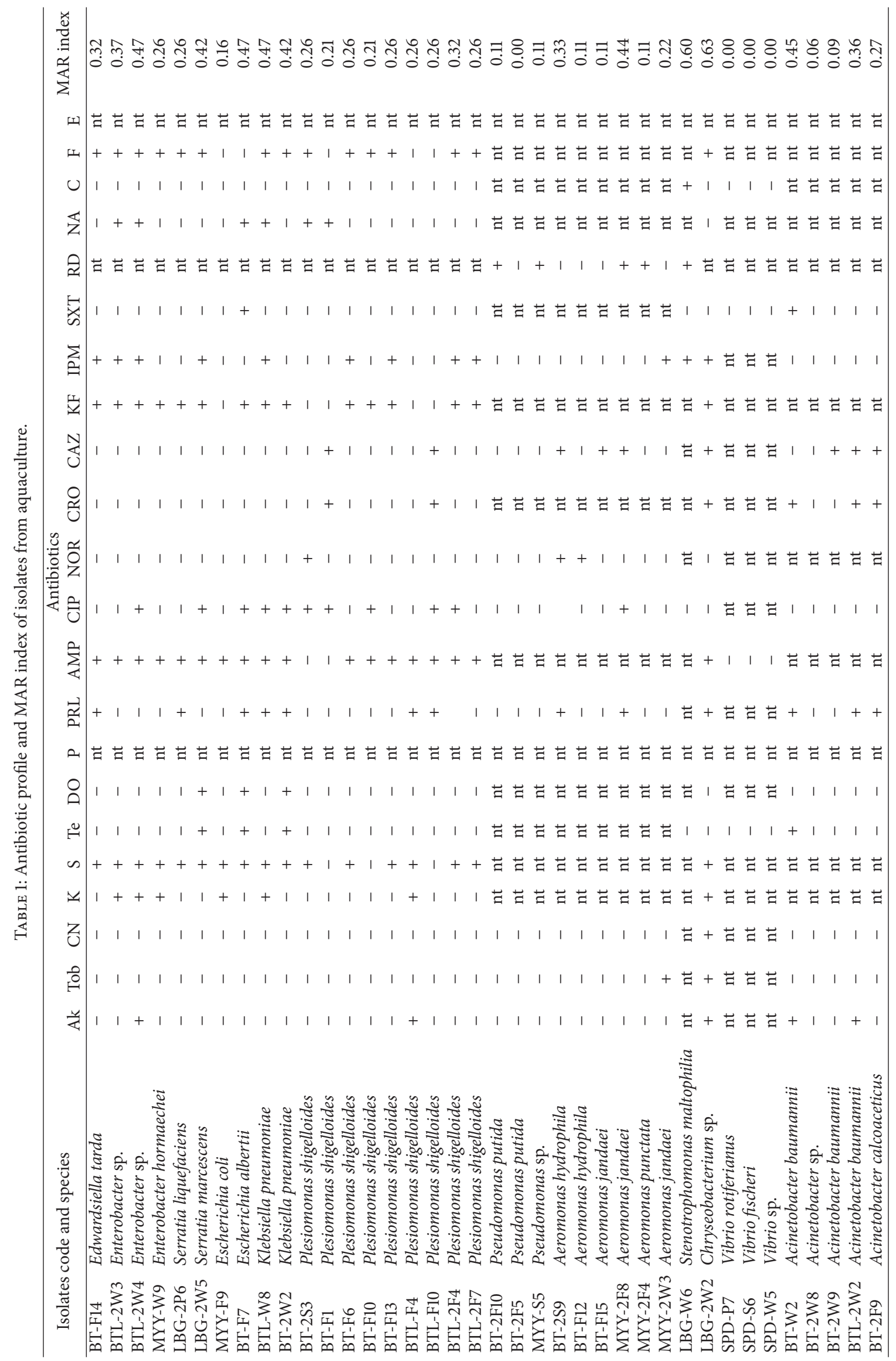




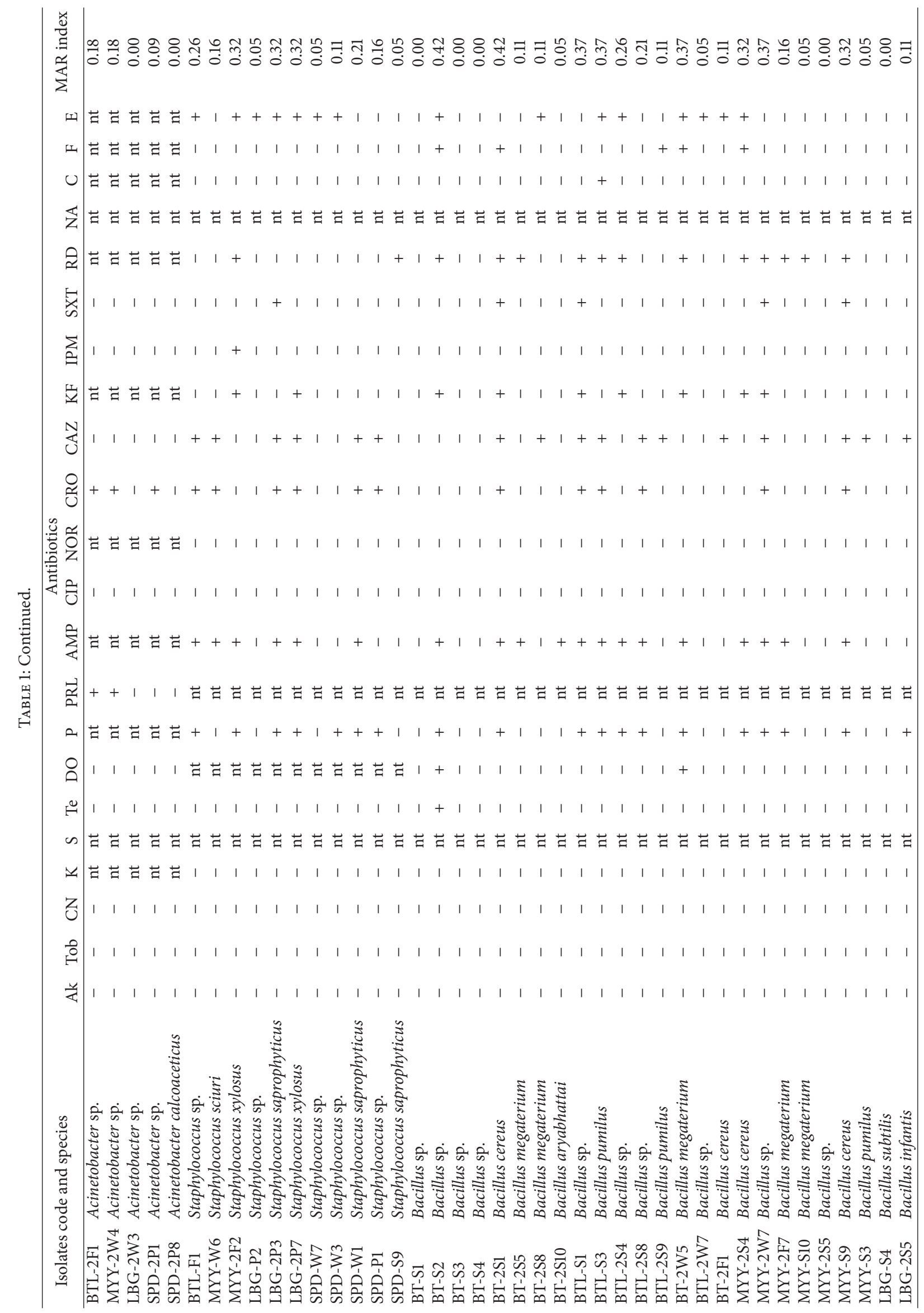




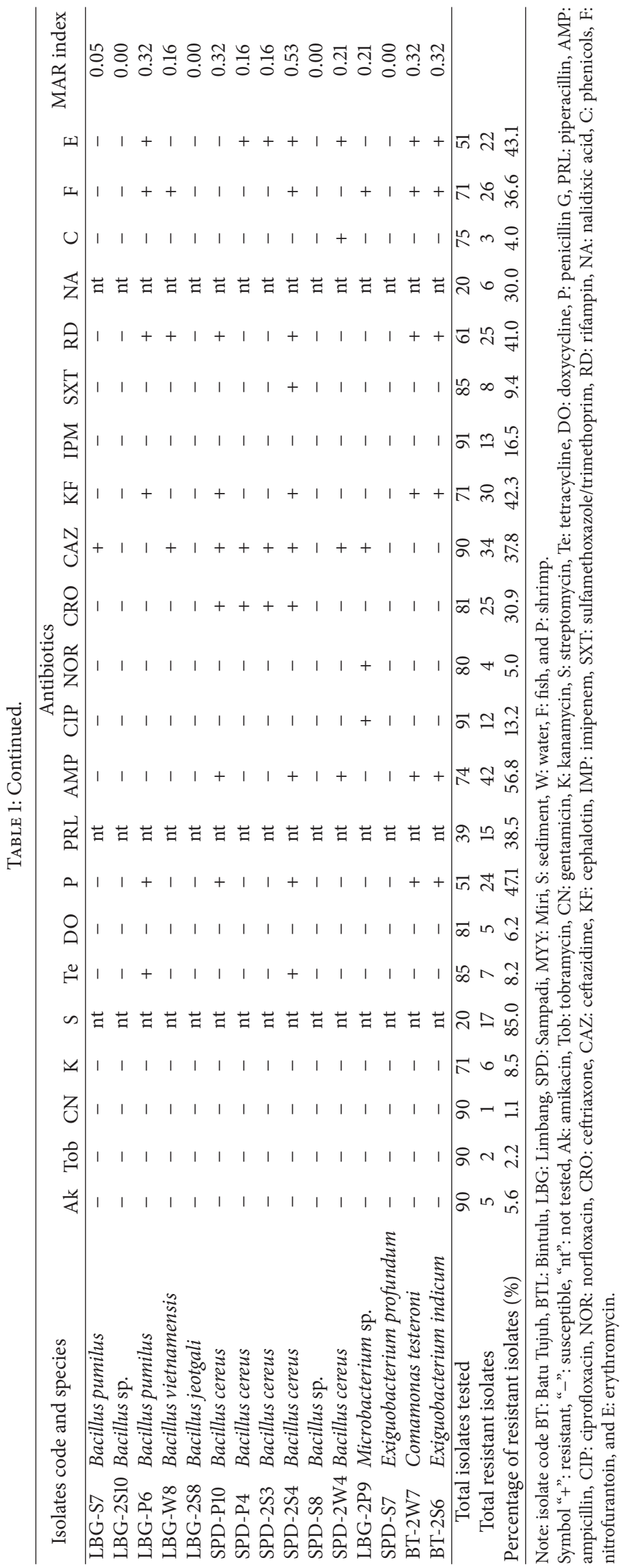




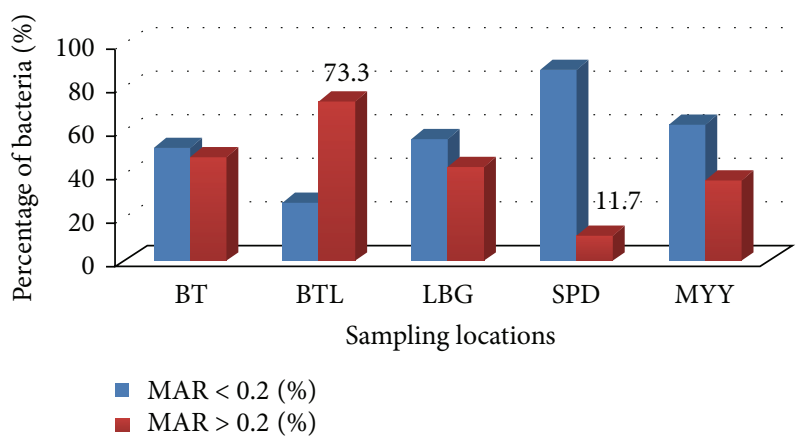

FIGURE 1: MAR index analysis based on sampling locations; BT: Batu Tujuh (Seven Miles), BTL: Bintulu, LBG: Limbang, SPD: Sampadi, and MYY: Miri.

as isolates recovered from low risk sources of contamination while isolates with MAR $>0.2$ were from high risk sources [27]. In this study, the MAR index ranged from 0 to 0.63 . Analysis on overall isolates regardless of sampling location revealed that $63.1 \%(n=94)$ isolates belong to group MAR $<0.2$ while $36.9 \%(n=94)$ isolates belong to group MAR > 0.2 . MAR index was also assessed according to the sampling location (Figure 1). Bintulu (BTL) has the highest percentage (73.3\%, $n=16)$ of bacteria isolated from high antibioticcontaminated sources while Sampadi (SPD) has the lowest percentage $(11.7 \%, n=17)$.

\section{Discussion}

Assessment of the antibiotic resistance among aquaculture bacteria against antimicrobial agents is important for update on the bacterial antibiotic resistance patterns. It is part of a surveillance system aiming at monitoring emerging antibiotic resistant bacteria and their widespread. Isolation of antibiotic resistant bacteria from aquaculture products and aquaculture environment indicates the health risk associated with the aquaculture. There had been reports on detection of antibiotic resistance genes in bacteria isolated from aquaculture products that can be transferred to human microbiota. This matter is becoming critical if the resistance genes are transferrable to human pathogens. Providing effective treatment towards this infection becomes a problem to the medical practitioners as the choice of antibiotics is limited. Thus, any source of antibiotic resistant bacteria must be carefully monitored [4].

In antibiotic resistance analysis, the history of antibiotic application in particular area is reflected by the percentage of bacterial resistance to antibiotics [21]. The frequency of antibiotics usage is related to the level of resistance among bacteria [2, 29]. In this present study, high percentage of susceptibility was observed towards gentamicin, tobramycin, and chloramphenicol. Similarly, Lim and Kasing [21] and Hatha et al. [17] in their respective studies observed that almost none of the bacteria tested were resistant to gentamicin and chloramphenicol. Low frequency of antibiotic resistant bacteria may indicate the less activity associated with the contamination of antibiotics in the area.
The use of chloramphenicol in aquaculture has been banned in certain countries including Malaysia, Korea, and Japan since 1983 [30]. This is because of the adverse effect of chloramphenicol in humans, even at very low dosage, which can cause other side effects like severe or fatal blood problems. The problems associated with blood are like anemia and "grey syndrome," a syndrome of cyanosis and cardiovascular collapse, which occurs particularly in newborn babies. This poses risks to the workers handling the products containing this antibiotic [5, 31]. Banning of antibiotics has aided in reducing the number of antibiotic resistant bacteria in an environment. This present study revealed very low percentage of resistance towards chloramphenicol (4\%). Aarestrup et al. [32] reported the significant reduction in the frequency of vancomycin-resistant Enterococci from broiler after the banning of vancomycin in Denmark in 1995. This proves that government involvement in preventing dissemination of antibiotic resistant bacteria is important.

High percentage of streptomycin, ampicillin, and penicillin $G$ resistance was observed in this study. Similarly, high ampicillin and streptomycin resistance were also observed by Zhang et al. [33] in their study on antibiotic resistance detection in $E$. coli strains isolated from two different aquaculture systems in South China. Hatha et al. [17] also recorded high resistance of ampicillin. In another study, identified isolates from mangrove soil in Malaysia were 100\% resistant towards ampicillin and penicillin while $77.8 \%$ of the isolates were resistant towards streptomycin [34]. Son et al. [35] in their study on Aeromonas hydrophila isolated from Tilapia mossambica recorded $100 \%$ ampicillin resistance and 57\% streptomycin resistance. Abdullahi et al. [36] observed $100 \%$ ampicillin resistance in Pseudomonas spp. isolated from Sarawak aquaculture environment. A study carried out by Akinbowale et al. [15] recorded 54.8\% ampicillin resistance of aquaculture bacteria in Australia. In contrast with the results in this study, low resistance of streptomycin $(21.2 \%)$ and ampicillin (6.1\%) was observed in a study on 33 marine bacteria isolates by You et al. [37].

In this study, farmers in the aquaculture farms where the sampling was carried out stated that there was no history of utilization of antibiotics in their farms. Despite the absence of antibiotics as medicines or in feeds, high resistance was observed to commonly used antibiotics such as streptomycin, ampicillin, and penicillin. High resistance of ampicillin and streptomycin in this study and other researches was not surprising as these antibiotics were among the first antibiotics introduced since the discovery of penicillin [38]. Although antibiotic usage in the studied farms has been stopped decades ago, antibiotic contamination is still possible as there may still be residues of antibiotics left in the environment. Bacteria isolated from the sediment of the aquaculture pond may have acquired antibiotic resistance characteristics through unconsumed foods and the cultured organism's faeces that contain the remaining antibiotics [3941]. The unconsumed foods and faeces will be deposited in the sediment and the composition of sediment microbiota will be altered due to selective pressure [39]. Fish feeds were a possible reservoir for antibiotic resistant genes in the farm sediments [41]. 
In this present study, Bintulu (BTL) recorded the highest percentage $(73.3 \%, n=16)$ of bacteria isolated from high antibiotic-contaminated sources (MAR > 0.2) while Sampadi (SPD) aquaculture farm recorded the least number $(11.7 \%$, $n=17$ ) of MAR index $>0.2$ isolates. The high number of bacteria with MAR $>0.2$ was found in Bintulu. The aquaculture farm is located at an area that has many agriculture activities (e.g., pig farming, duck farming, and dragon fruit cultivation) surrounding it. There is the possibility that antibiotics from the animal feeds or medications were absorbed into the sediment causing bacterial selection in the nearby environment. Multiple antibiotic resistant bacteria might have travelled through water from these agriculture activities to the aquaculture ponds. Buschmann et al. [42] in their study suggested that antibiotic resistant bacteria in mariculture farm may be transported by water current which flows from surrounding farms that utilize antibiotics excessively. Antibiotic resistance pattern may vary depending on the geographical locations and selective pressure $[43,44]$ and these patterns change rapidly from time to time.

The different patterns exhibited by different strains or species suggest how complex is the understanding of the antibiotics resistance in the study area. In this study, the resistance patterns were highly variable; $20.2 \%(n=94)$ isolates have no resistance towards any antibiotics tested, $16 \%$ $(n=94)$ isolates were resistant to only one antibiotic, and $63.8 \%(n=94)$ isolates were resistant to multiple antibiotics.

Awareness on antibiotic resistance threat should be instilled in the community regardless of age as precaution and prevention step against dissemination of antibiotic resistant bacteria. The community must be educated on antibiotics and their effects on public health. Many surveillance programs had also been introduced to monitor the emergence and spread of antibiotic resistant bacteria. It has also been suggested by Son et al. [4] that plasmid screening should be considered as an additional procedure in the monitoring programs to trace antibiotic resistance dissemination. Alternatives to treatment using antibiotics like probiotics, vaccines, and antimicrobials from plants should be also considered. However, most of the alternatives could not really effectively replace antibiotics, so they act as additional preventive measures rather than alternatives.

\section{Conclusion}

The MAR indexing has revealed that $63.1 \%$ of the isolates came from low antibiotic usage area. Although antibiotic resistance in aquaculture in the Malaysian Borneo is still in its infancy, the need for continuous monitoring of the antibiotic resistance patterns should not be overlooked and the community should be educated on the awareness of antibiotic resistance and its implication on human health and environment.

\section{Competing Interests}

The authors declare that they have no competing interests.

\section{Acknowledgments}

This research study was supported by research Grant no. FRGS/01(16)/745/2010(31) and Department of Molecular Biology, Faculty of Resource Science and Technology, Universiti Malaysia Sarawak.

\section{References}

[1] K. H. Ng, L. Samuel, M. M. Kathleen, S. S. Leong, and C. Felecia, "Distribution and prevalence of chloramphenicol-resistance gene in Escherichia coli isolated from aquaculture and other environment," International Food Research Journal, vol. 21, no. 4, pp. 1321-1325, 2014.

[2] L. Samuel, M. M. Marian, K. Apun, M. B. Lesley, and R. Son, "Characterization of Escherichia coli isolated from cultured catfish by antibiotic resistance and RAPD analysis," International Food Research Journal, vol. 18, no. 3, pp. 971-976, 2011.

[3] M. R. Dorsch, "Rapid detection of bacterial antibiotic resistance: preliminary evaluation of PCR assays targeting tetracycline resistance genes," Tech. Rep., Human Protection and Performance Division, 2007.

[4] R. Son, G. Rusul, and M. I. A. Karim, "Conjugal transfer of plasmids and antibiotic resistance among Escherichia coli isolated from animals in a rural area in Sarawak (Malaysia)," Journal of Applied Microbiology, vol. 82, no. 2, pp. 240-244, 1997.

[5] M. Shariff, G. Nagaraj, F. H. C. Chua, and Y. G. Wang, "The use of chemicals in aquaculture in Malaysia and Singapore," in Use of Chemicals in Aquaculture in Asia, J. R. Arthur, C. R. Lavilla Pitogo, and R. P. Subasinghe, Eds., pp. 127-140, Southeast Asian Fisheries Development Centre, Aquaculture Department, Iloilo, Philippines, 2000.

[6] M. J. Pelczar, E. C. S. Chan, N. R. Krieg, and M. F. Pelczar, Eds., Microbiology, McGraw-Hill, New York, NY, USA, 5th edition, 1986.

[7] C. M. Benbrook, "Antibiotic drug use in U.S. aquaculture," Institute for Agriculture and Trade Policy (IATP) Report, 2002.

[8] H. Supriyadi and A. Rukyani, "The use of chemicals in aquaculture in Indonesia," in Use of Chemicals in Aquaculture in Asia: Proceedings of the Meeting on the Use of Chemicals in Aquaculture in Asia 20-22 May 1996, Tigbauan, Iloilo, Philippines, J. R. Arthur, C. R. Lavilla-Pitogo, and R. P. Subasinghe, Eds., pp. 113-118, Aquaculture Department, Southeast Asian Fisheries Development Center, Iloilo, Philippines, 2000.

[9] M. A. Akond, S. M. R. Hassan, S. Alam, and M. Shirin, "Antibiotic resistance of Escherichia coli isolated from poultry and poultry environment of bangladesh," American Journal of Environmental Sciences, vol. 5, no. 1, pp. 47-52, 2009.

[10] J. L. Ríos and M. C. Recio, "Medicinal plants and antimicrobial activity," Journal of Ethnopharmacology, vol. 100, no. 1-2, pp. 8084, 2005.

[11] T. Rahman, M. M. R. Akanda, M. M. Rahman, and M. B. R. Chowdhury, "Evaluation of the efficacies of selected antibiotics and medicinal plants on common bacterial fish pathogens," Journal of the Bangladesh Agricultural University, vol. 7, no. 1, pp. 163-168, 2010.

[12] C. Wong, P. Proksch, L. T. Tan, S. Lihan, A. Mujahid, and M. Muller, "Isolation, identification and screening of antimicrobial properties of the marine-derived endophytic fungi from marine brown seaweed," Microbiology Indonesia, vol. 9, no. 4, 2015.

[13] S. Lihan, C. S. Lin, I. Ahmad, F. M. Sinang, N. K. Hua, and A. A. Sallehin, "Antimicrobial producing microbes isolated from 
soil samples collected from Nanga Merit Forest in Sarawak, Malaysian Borneo," European Journal of Experimental Biology, vol. 4, no. 1, pp. 494-501, 2014.

[14] C. J. Rodgers and M. D. Furones, "Antimicrobial agents in aquaculture: practice, needs and issues," in The Use of Veterinary Drugs and Vaccines in Mediterranean Aquaculture, no. 86, pp. 41-59, IRTA-Centre d'Aquicultura, Ctra. PobleNou, SantCarles de la Rapita, Tarragona, Spain, 2009.

[15] O. L. Akinbowale, H. Peng, and M. D. Barton, "Antimicrobial resistance in bacteria isolated from aquaculture sources in Australia," Journal of Applied Microbiology, vol. 100, no. 5, pp. 1103-1113, 2006.

[16] Y. Zulkifli, N. B. Alitheen, A. R. Raha et al., "Antibiotic resistance and plasmid profiling of Vibrio parahaemolyticus isolated from cockles in Padang, Indonesia," International Food Research Journal, vol. 16, no. 1, pp. 53-58, 2009.

[17] M. Hatha, A. A. Vivekanandhan, G. Julie Joice, and Christol, "Antibiotic resistance pattern of motile aeromonads from farm raised fresh water fish," International Journal of Food Microbiology, vol. 98, no. 2, pp. 131-134, 2005.

[18] J. Davies, "Inactivation of antibiotics and the dissemination of resistance genes," Science, vol. 264, no. 5157, pp. 375-382, 1994.

[19] S. Suzuki, "Tetracycline resistance gene in Asian aquatic environments," in Interdisciplinary Studies on Environmental Chemistry-Biological Responses to Contaminants, N. Hamamura, S. Suzuki, S. Mendo, C. M. Barroso, H. Iwata, and S. Tanabe, Eds., pp. 1-8, Terrapub, Tokyo, Japan, 2010.

[20] S. Gräslund, K. Holmström, and A. Wahlström, "A field survey of chemicals and biological products used in shrimp farming," Marine Pollution Bulletin, vol. 46, no. 1, pp. 81-90, 2003.

[21] M. H. Lim and A. Kasing, "Antimicrobial susceptibilities of Vibrio parahaemolyticus isolates from tiger shrimps (Penaeus monodon) aquaculture in Kuching, Sarawak," Research Journal of Microbiology, vol. 8, no. 1, pp. 55-62, 2013.

[22] G. Huys, "Sampling and sample processing procedures for the isolation of aquaculture-associated bacteria," Standard Operating Procedures, 2003.

[23] M. M. Kathleen, L. Samuel, C. Felecia, K. H. Ng, M. B. Lesley, and A. Kasing, "(GTG) $)_{5}$ PCR analysis and 16s rRNA sequencing of bacteria from Sarawak aquaculture environment," International Food Research Journal, vol. 21, no. 3, pp. 915-920, 2014.

[24] Clinical and Laboratory Standards Institute, Performance Standards for Antimicrobial Susceptibility Testing: Nineteenth Information Supplement, CLSI, 2009.

[25] Clinical and Laboratory Standards Institute (CLSI), Performance Standards for Antimicrobial Susceptibility Testing: Nineteenth Information Supplement, CLSI, Pennsylvania, Pa, USA, 2012.

[26] R. Bonnet, Comité de I’Antibiogramme de la Société Française de Microbiologie, CASFM, 2012.

[27] P. H. Krumperman, "Multiple antibiotic resistance indexing of Escherichia coli to identify high-risk sources of fecal contamination of foods," Applied and Environmental Microbiology, vol. 46, no. 1, pp. 165-170, 1983.

[28] O. Osundiya, R. Oladele, and O. Oduyebo, "Multiple Antibiotic Resistance (MAR) indices of Pseudomonas and Klebsiella species isolates in Lagos University Teaching Hospital," African Journal of Clinical and Experimental Microbiology, vol. 14, no. 3, pp. 164-168, 2013.
[29] D. J. Austin, K. G. Kristinsson, and R. M. Anderson, "The relationship between the volume of antimicrobial consumption in human communities and the frequency of resistance," Proceedings of the National Academy of Sciences of the United States of America, vol. 96, no. 3, pp. 1152-1156, 1999.

[30] M. H. Yoo, M.-D. Huh, E.-H. Kim, H.-H. Lee, and H. D. Jeong, "Characterization of chloramphenicol acetyltransferase gene by multiplex polymerase chain reaction in multidrug-resistant strains isolated from aquatic environments," Aquaculture, vol. 217, no. 1-4, pp. 11-21, 2003.

[31] K. Li, L. Liu, C. L. Xu, and X. G. Chu, "Rapid determination of chloramphenicol residues in aquaculture tissues by immunochromatographic assay," Analytical Sciences, vol. 23, no. 11, pp. 1281-1284, 2007.

[32] F. M. Aarestrup, F. Bager, N. E. Jensen, M. Madsen, A. Meyling, and H. C. Wegener, "Surveillance of antimicrobial resistance in bacteria isolated from food animals to antimicrobial growth promoters and related therapeutic agents in Denmark," Acta Pathologica, Microbiologica, et Immunologica Scandinavica, vol. 106, no. 6, pp. 606-622, 1998.

[33] R.-Q. Zhang, G.-G. Ying, H.-C. Su, L.-J. Zhou, and Y.-S. Liu, "Antibiotic resistance and genetic diversity of Escherichia coli isolates from traditional and integrated aquaculture in South China," Journal of Environmental Science and Health, Part B Pesticides, Food Contaminants, and Agricultural Wastes, vol. 48, no. 11, pp. 999-1013, 2013.

[34] K. C. A. Jalal, U. T. Nur Fatin, M. A. Mardiana et al., "Antibiotic resistance microbes in tropical mangrove sediments in east coast peninsular, Malaysia," African Journal of Microbiology Research, vol. 4, no. 8, pp. 640-645, 2010.

[35] R. Son, G. Rusul, A. M. Sahilah, A. Zainuri, A. R. Raha, and I. Salmah, "Antibiotic resistance and plasmid profile of Aeromonas hydrophila isolates from cultured fish, Telapia (Telapia mossambica)," Letters in Applied Microbiology, vol. 24, no. 6, pp. 479482, 1997.

[36] R. Abdullahi, S. Lihan, S. B. Carlos, L. M. Bilung, K. M. Mikal, and F. Collick, "Detection of oprL gene and antibiotic resistance of Pseudomonas aeruginosa from aquaculture environment," European Journal of Experimental Biology, vol. 3, pp. 148-152, 2013.

[37] K. G. You, C. W. Bong, and C. W. Lee, "Antimicrobial resistance in bacteria isolated from tropical coastal waters of peninsular Malaysia," Malaysia Journal of Science, vol. 31, no. 2, pp. 111-120, 2012.

[38] G. J. Tortora, B. R. Funke, and C. L. Case, Microbiology: An Introduction, Pearson Benjamin Cummings by Pearson Education, Inc, San Francisco, Calif, USA, 9th edition, 2007.

[39] H. T. Tu, F. Silvestre, M.-L. Scippo, J.-P. Thome, N. T. Phuong, and P. Kestemont, "Acetylcholinesterase activity as a biomarker of exposure to antibiotics and pesticides in the black tiger shrimp (Penaeus monodon)," Ecotoxicology and Environmental Safety, vol. 72, no. 5, pp. 1463-1470, 2009.

[40] A. Noorlis, F. M. Ghazali, Y. K. Cheah et al., "Antibiotic resistance and biosafety of Vibrio cholerae and Vibrio parahaemolyticus from freshwater fish at retail level," International Food Research Journal, vol. 18, no. 4, pp. 1523-1530, 2011.

[41] M. Tamminen, A. Karkman, A. Lõhmus et al., "Tetracycline resistance genes persist at aquaculture farms in the absence of selection pressure," Environmental Science and Technology, vol. 45, no. 2, pp. 386-391, 2011. 
[42] A. H. Buschmann, A. Tomova, A. López et al., "Salmon aquaculture and antimicrobial resistance in the marine environment," PLoS ONE, vol. 7, no. 8, Article ID e42724, 2012.

[43] K. Satyanarayana, "Detection of antimicrobial resistance in common gram negative and gram positive bacteria encountered in infectious disease-an update," ICMR Research Information Bulletin, vol. 3, pp. 1-3, 2009.

[44] M. B. Lesley, L. Velnetti, Y. K. Cheah et al., "Antibiotic resistance and plasmid profiling of vibrio parahaemolyticus isolated from cockles (Anadara granosa) at Tanjung Karang, Kuala Selangor," International Food Research Journal, vol. 18, no. 3, pp. 1183-1188, 2011. 

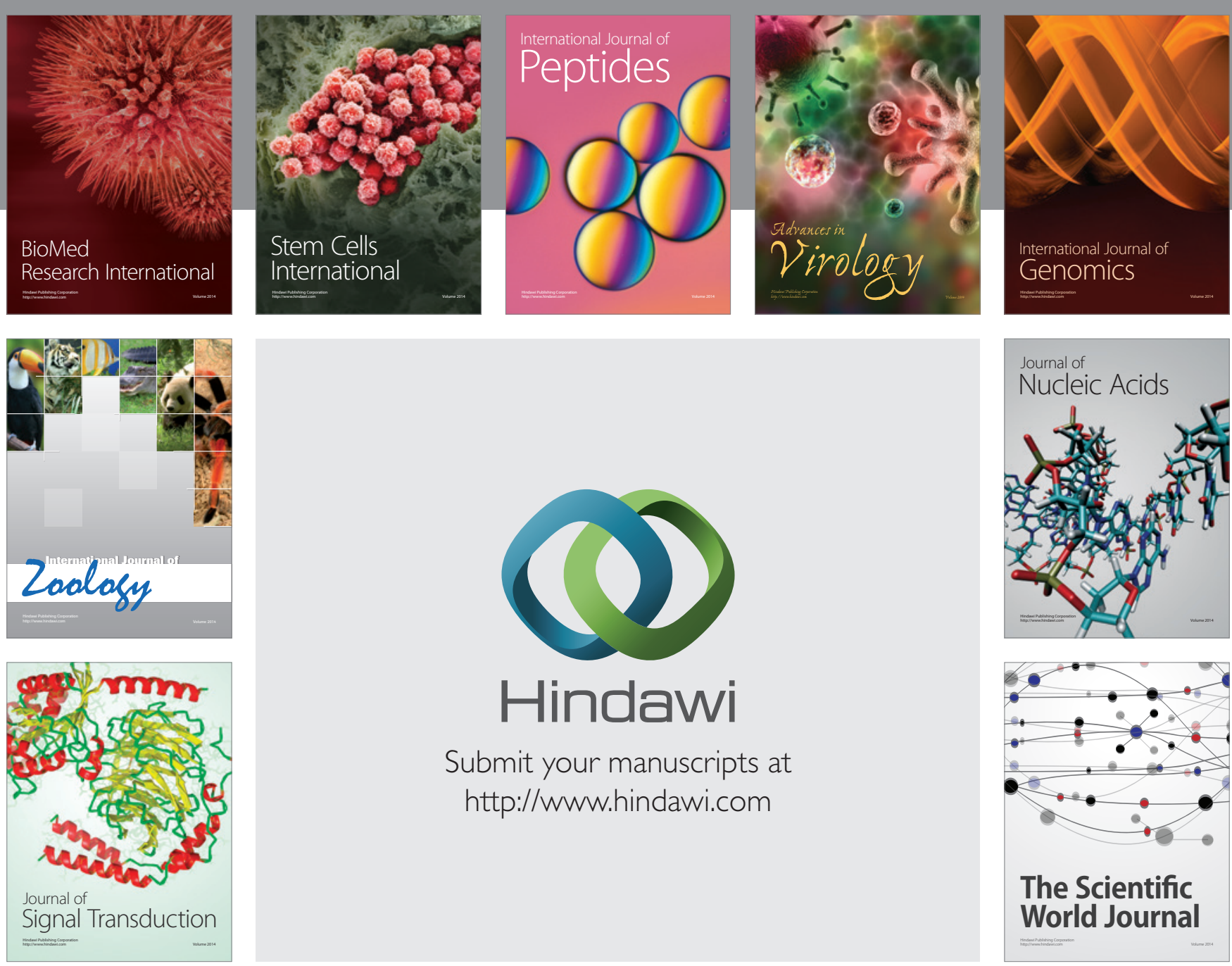

Submit your manuscripts at

http://www.hindawi.com
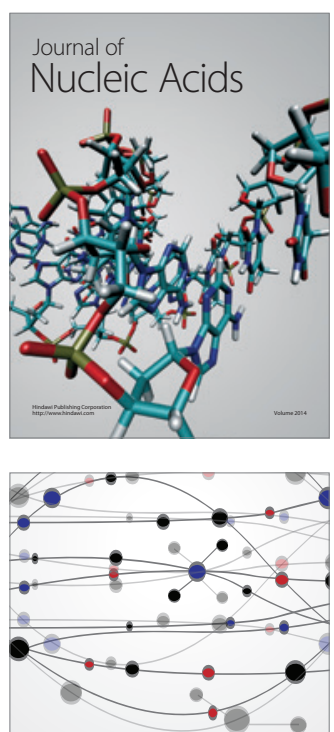

The Scientific World Journal
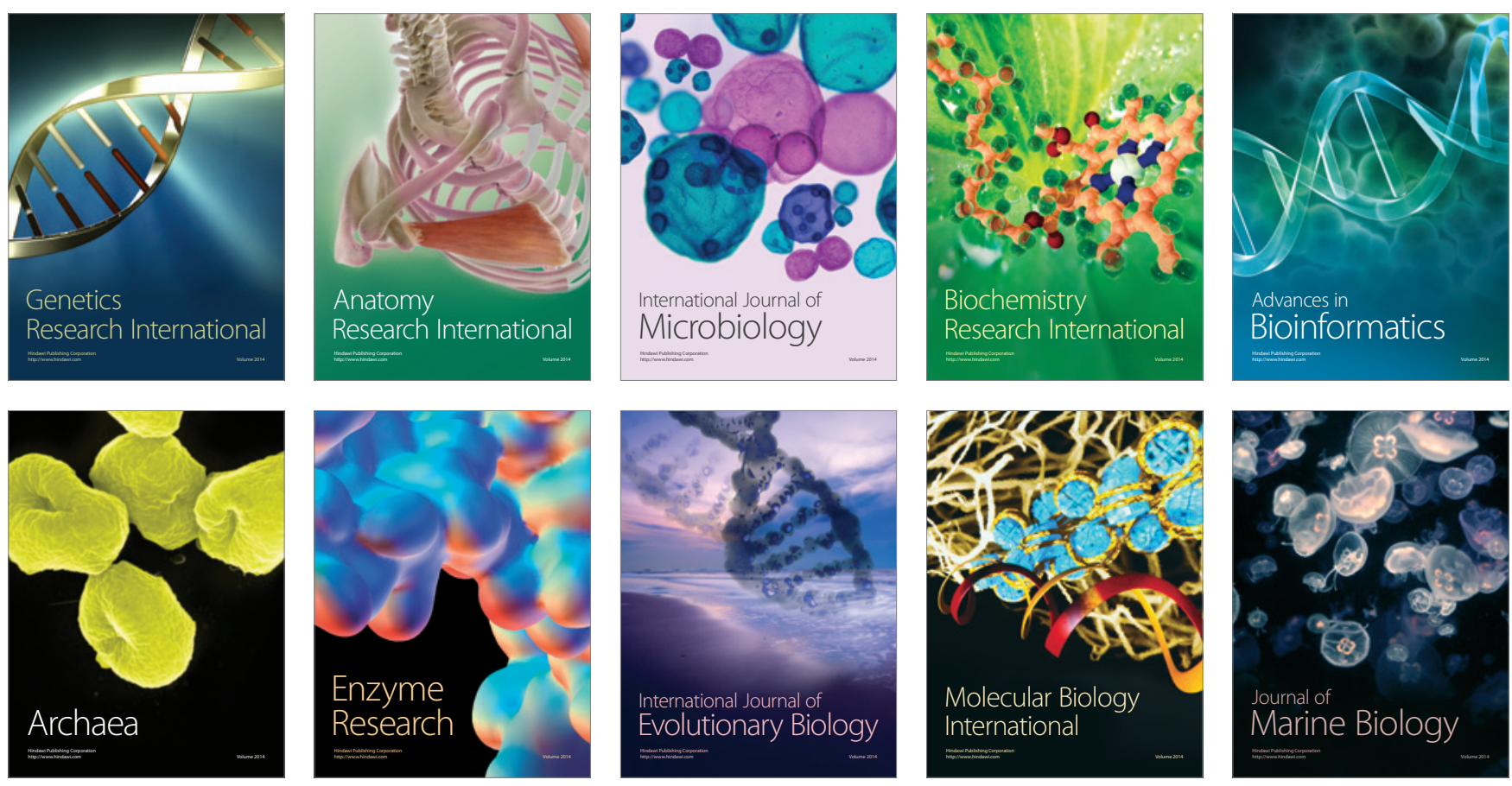